\title{
Developing a reform mathematics curriculum program in Sweden: relating international research and the local context
}

\author{
Hendrik Van Steenbrugge ${ }^{1}$ [D $\cdot$ Andreas Ryve ${ }^{1}$
}

Accepted: 14 July 2018 / Published online: 21 August 2018

(c) The Author(s) 2018

\begin{abstract}
This paper reports on a research-based mathematics curriculum program development project in Sweden, whose educational context is currently characterized by multiple reform initiatives. Current reforms include a repositioning of the teacher as central for students' learning, but also a trend toward initiatives and teacher resources that are more directive than has been the case in the past 30 years. Collecting data from multiple sources, such as teacher log books, lesson observations and feedback meetings, we build on input from 11 elementary school teachers trying out our materials, including student texts and a teachers' guide, during four trial rounds. We analyze how international research about curriculum programs and teachers' use of these programs are interpreted and operationalized within the Swedish context. In particular, the two research questions guiding the study are: (1) "How do Swedish teachers interact with and reason about the reform-based classroom practices promoted by the curriculum program?" and (2) "How do Swedish teachers interact with and reason about their use of a teachers' guide?" From our experiences in the Swedish educational context, we suggest the following contextual aspects to take into account when designing a curriculum program whose design is grounded in international research literature: characteristics of current classroom practices, teachers' role in classrooms, the level of explicit/implicit support teachers are used to receiving, and teachers' experiences using a teachers' guide.
\end{abstract}

\section{Introduction}

The design and use of mathematics curriculum programs, including teachers' guides and student textbooks, has received considerable attention within mathematics education research (e.g., Davis et al. 2014; Hill and Charalambous 2012). As a result, international theories and frameworks have been developed and serve as important input in processes of designing, developing and establishing reformbased curriculum programs. Also, it has been argued that teachers' use of curriculum programs has to be understood in a broader system of educational context and curriculum policy (Remillard and Heck 2014). While it is obvious that contextual aspects matter, it is more difficult to conceptualize the context, specify its essential aspects, and how these aspects influence the design and enactment of curriculum programs (e.g., Bryk et al. 2015). In this paper, we aim to

Hendrik Van Steenbrugge

hendrik.van.steenbrugge@mdh.se

1 School of Education, Culture and Communication, Mälardalen University, Högskoleplan 1, Rosenhill, Västerås, Sweden contribute to research on the relation between international theories and educational context in designing curriculum programs in mathematics. In particular, we are interested in how teachers within the Swedish educational context interact with and reason about a research-based curriculum program. We do so based on the initial 2-year design phase of a grade 1-3 research-based reform mathematics curriculum program in Sweden.

We use the term curriculum programs to refer to the whole set of resources assembled to guide teaching and learning. Such a program typically includes materials for the students such as textbooks, and for teachers such as a teachers' guide, as well as additional didactical materials. Because we understand the teachers' guide as a premium medium to communicate with teachers about the intended practices, we focus on the teachers' guide. Research questions guiding the study are as follows:

1. How do Swedish teachers interact with and reason about the reform-based classroom practices promoted by the curriculum program?

2. How do Swedish teachers interact with and reason about their use of a teachers' guide? 
We relate findings on these two questions to characteristics of the Swedish educational context. In the following three sections, we describe respectively the theoretical frameworks and research we are drawing on in the development project, the Swedish mathematics educational context, and the development project, which helps the reader to understand the basis for the development, but also to situate the findings in the specific context. The findings are discussed, relating them to the Swedish context, in a final section.

\section{Theoretical frameworks and related research as a basis to design teacher support}

The basic assumption we are building on is the conception that the relationship between the teacher and the curriculum program is a dynamic interrelationship (Brown 2009; Gueudet and Trouche 2009; Remillard 2005). This conception builds on a socio-cultural perspective in which the teacher-curriculum program relationship is an example of the agent-tool relationship as proposed by Vygotsky (1978). Along this line, curriculum programs are conceived as cultural tools that reflect and mediate the cultural practice of teaching mathematics. As such, it follows that curriculum programs can support and constrain teachers in establishing teaching practices. This conceptualization of the teachercurriculum program relationship has been supported by empirical findings. For instance, Hill and Charalambous' (2012) cross-case analysis of teachers' use of a challenging mathematics curriculum program revealed a unique as well as joint contribution of teachers' knowledge and curriculum programs to the quality of instruction.

Although both the teacher and the curriculum program can contribute complementarily to the establishment of mathematics lessons, the focus in this paper is on the curriculum program's potential contribution, taking into account the specific educational context. We do not disregard teachers' contributions; rather we analyze teachers' interactions with and reasoning about the new curriculum program to better understand how curriculum programs can contribute to the cultural practice of teaching mathematics.

Ball and Cohen (1996) have argued that "Materials could be designed to place teachers in the center of curriculum construction and make teachers' learning central to efforts to improve education, without requiring heroic assumptions about each teacher's capacities as an original designer of curriculum" (p. 7). Along this line, Remillard (2000) argued that curriculum programs should be designed to talk to the teacher about the particular teaching approach rather than merely through the teacher by directing her/his actions. Davis and Krajcik (2005) proposed design heuristics for such educative curriculum programs. Since then, research has pointed to the importance of these design heuristics for the actual teaching. Several studies have suggested or revealed that in order to support teacher learning, it is important that designers of curriculum programs be explicit about their intent with lessons, activities and tasks (Davis et al. 2011; Stein and Kim 2009), assist the teacher in anticipating student thinking (Choppin 2011a; Davis et al. 2011; Stein and Kim 2009), and attend explicitly to the important mathematical ideas (Stein and Kaufman 2010).

Building on the abovementioned frameworks and findings, the central supports in the teachers' guide that talk to the teachers include a concrete description of a limited number of lesson goals related to a central mathematical idea per lesson, descriptions of the mathematical background, and student difficulties and errors. Whereas the benefit of having lesson goals for every single lesson might be selfevident to readers outside of Sweden, this is not at all the case in the Swedish context; goals are usually listed per chapter and sometimes described on a lesson-level. Further, a study of three teachers' use of a mathematics curriculum program revealed that teachers' understanding of how the program supports student thinking is crucial for the quality of adaptations to the curriculum program (Choppin 2011b). Choppin's study showed that the most productive adaptations were made by the teacher who understood the program's instructional sequence. Because of this, and because we know that Swedish teachers are used to following the content as sequenced in the student book (Boesen et al. 2014), we included support that talks to teachers about the instructional sequence as well. Inspired by Davis et al. (2014), the ICUBiT (Improving Curriculum Use for Better Teaching) project (Remillard 2013), and our own analysis of teachers' guides from Sweden, the USA, and Flanders ${ }^{1}$ (Van Steenbrugge et al. 2015), we included three related types of supports. First is a description of how the content of a series of lessons builds on prior knowledge and prepares for future knowledge. Second is a description of how the lessons within a lesson series relate to one another. Third, we included support that spoke to the teachers about the sequence within a lesson by means of previewing lesson phases and activities, describing the connections between lesson phases, and describing when to move on to a next lesson phase.

The abovementioned frameworks and findings allocate to the teacher a central proactive role in establishing classroom practices. As elaborated below concerning the Swedish educational context, teachers have a reactive rather than a proactive role, and the tendency to empower teachers has

\footnotetext{
${ }^{1}$ Flanders is the Dutch speaking part of Belgium with its own educational system.
} 
been through an implicit pedagogy. Taking this aspect into account, and given that we aim to reorganize rather than strengthen current practices, these concerns led us to consider to what extent curriculum programs should speak to rather than through teachers. We were inspired by Remillard and Reinke (2012), who suggested that directive support for teachers, to some extent, can be educative, especially for inexperienced teachers or when trying out unfamiliar practices, because they can "offer new pedagogical repertoire and routines, allowing teachers to consider and try out new questions to ask, words to use, and instructional moves to make" (p. 13). This led us to include also supports that are directive in nature. These supports include the explicit structuring of lessons, use of lesson slides, provision of principles for productive discussions, and the routine to end lessons by means of assigning exit tickets. The following section describes the Swedish educational context to help to situate teachers' reactions to these included supports.

\section{Mathematics education in Sweden: relevant aspects for the design of curriculum programs}

As elaborated by Ryve et al. (2016), several features of the Swedish context are of relevance in implementing educational policies and designing professional development programs for teachers. We argue that the same holds for the design of mathematics curriculum programs within the Swedish educational context, and thus we introduce below essential aspects of the Swedish educational context.

Analyses of 197 Swedish mathematics lessons (Boesen et al. 2014), as well as studies of discourses about effective teaching (Hemmi and Ryve 2015) show that teachers have had a rather passive role in classrooms when it comes to specifying lesson goals, monitoring group work and orchestrating classroom discussions. The teacher's main role, instead, has been to be responsive to students' thinking and encourage their motivation and personal responsibility for learning. Such a conception of teachers' work is also found in Swedish teachers' guides (e.g., Remillard et al. 2016). Analyses of Swedish teachers' guides reveal that teachers' major role in the classroom is to facilitate students' work on textbook tasks. In fact, it is hard to identify lessons in the textbooks and teachers' guides, and it is not assumed that teachers should frequently introduce or summarize lessons. This aspect reflects a dominant discourse in Sweden that instructional moves, such as teachers introducing, explaining and discussing mathematical content, are not central aspects of mathematical classroom practices (Ryve et al. 2016). Therefore, the nature of classroom practices, discourses on teachers' work, as well as their lack of experience in making lesson plans, introducing mathematical content and orchestrating whole-class discussions, strongly mediated our design and construction of curriculum programs.

The role of the teacher in the classroom is connected to traditions of a specific view regarding the empowerment of teachers in Sweden. That is, neither steering documents, teacher education programs, nor teachers' guides, include detailed lesson plans, suggestions for teacher moves or teaching plans for semesters (Hemmi and Ryve 2015; Ryve et al. 2013). In the words of Kennedy (2016), who reviewed professional development initiatives in the USA, the underlying assumption has been that teachers and teaching develop through building teachers' broad knowledge base rather than by introducing, elaborating on and implementing teaching strategies. The empowerment of teachers has been realized, not through what Fowler and Poetter (2004) would call making teaching and pedagogy visible, but instead through distributing this responsibility to the teachers themselves. In line with this view, the idea that teachers adhere to the structure of curriculum programs, i.e., teachers' guides and student textbooks, and use them in planning and enacting teaching, has been criticized by the national agencies and teacher educators (Ryve et al. 2016). Interestingly, and as discussed above, classrooms in Sweden have often been characterized by students working silently with their textbooks, with the teacher guiding individual students in their work (Boesen et al. 2014). Thus, the use of the students' textbooks in the mathematics classroom is not in line with the discourses of national agencies and researchers concerning teacher education programs about not adhering too closely to the structure of curriculum programs during the planning and enactment of teaching. Students' individual work from textbooks has often resulted in progressing at their own pace in different mathematical areas, making whole-class activities both difficult and uncommon (Ryve et al. 2016). The invisible pedagogy in Sweden and our extensive experience working with teachers show that teachers both strongly appreciate explicit frameworks and strategies for teaching, and that such frameworks increase their engagement in collegial discussions. Consequently, these features of the Swedish context influenced the design and construction of the programs.

\section{The development project}

\subsection{Background to the project}

For a number of years, the research group in mathematics education at Mälardalen University has been engaged in examining mathematics curriculum programs in Sweden, Finland, the USA, and Flanders (e.g., Hemmi et al. 2017; Remillard et al. 2016; Van Steenbrugge et al. 2015). Additionally, within initiatives to improve mathematics instruction at scale rolled out in a medium sized city and managed 
by the research group (Ryve et al. 2016), we have explicitly included the use of curriculum programs as a central component in planning, enacting and reflecting on mathematics teaching. Indeed, these two overarching activities (improvement at scale and analysis of curriculum programs) have built a knowledge capacity within the research group as well as a strong driving force for improving the quality of mathematics curriculum programs in Sweden.

However, research foundations, including the Swedish Research Council, have not announced calls for funding the design of research-based curriculum programs. Therefore, funding the project has been a major issue. Further, developed curriculum programs are not evaluated. Although the Swedish Association of Educational Publishers adopted a quality policy, albeit very general and brief (Svenska Läromedel 2018), anyone can produce and sell mathematics curriculum programs. Authorities in Sweden, such as the National Agency of Education and School Inspectorate, pay very little attention to curriculum programs-besides that they have commented that teachers should not rely on them. This lack of legal regulations and funding, as well as the fact that students' textbooks are used extensively in Swedish classrooms (Boesen et al. 2014), has resulted in curriculum programs being developed by practicing teachers, during their spare time, together with commercial publishers. Within this educational context, we set out to find funding and start developing a research-based curriculum program and succeeded in obtaining funding (1.5 M Euros) from a bank collaborating with a municipality to carry out the design of a mathematics curriculum program for Grades 1-3 (2016-2020). Our experience from working with the bank and municipality during the past 2 years is that they do not, in any way, try to steer either the process or the content of the curriculum programs.

\subsection{Process $^{2}$}

The project started off with a 6-month exploratory phase (January-June 2016), followed by a year and a half trial phase (August 2016-December 2017), and will include a 3 -year production phase (January 2018-December 2020).

In the exploratory phase, we engaged in surveying the field, connecting the Swedish educational context and the related research field. In addition to drawing on our own knowledge and experience in relation to the Swedish mathematics educational context, we explored related research (e.g., on curriculum program development and improving teaching at scale), had conversations with a variety of local

\footnotetext{
${ }^{2}$ We greatly appreciate the valuable input from the Center for Elementary Mathematics and Science Education at the University of Chicago.
}

stakeholders and developers of (research-based) curriculum programs from abroad, and held regular meetings within a reference group. Based on this survey, we determined the curriculum program's central goals, drafted a project plan and decided to team up with a Swedish publisher.

The development phase consisted of four trial rounds, alternating in Grades 1 and 2, with each round informing the next. This paper is based on the input from 11 teachers. In rounds $1-3$, introductory meetings were held to inform the teachers about the curriculum program's goals, envisioned classroom practices, teacher supports, and use of the materials. This was done because we know from implementation research that when trying out new practices, teachers tend to draw on their prior experience and beliefs (e.g., Century and Cassata 2016). In round 4, instead of holding an introductory meeting, we tried out video fragments that informed the teachers about the same aspects as in the face-to-face introductory meetings. As can be seen in Table 1, we drew on different data sources to inform ourselves about the teachers' use of the materials (see Sect. 5).

\section{Methods}

\subsection{Participants and data}

At the end of the 6-month exploratory phase, we announced the project in the participating municipality by means of contacting principals and organizing a meeting describing the project's goals and background with 20 head teachers, who then further communicated about the project with their colleagues at school. This process resulted in 16 experienced grade 1 or grade 2 teachers volunteering to participate in the study. Eight of the 16 teachers were interviewed to check on their views of teaching and learning of mathematics. Based on these interviews, and on the meetings with teachers, we describe the group of teachers to be moderately to highly aligned with the ideas behind the project.

We worked in total with a team of 16 teachers, but because we lack a considerable amount of data of 5 teachers, the findings in this paper are based on the input from 11 teachers: 5 grade 1 and 6 grade 2 teachers. Some teachers participated in several rounds. Teacher A participated in all rounds; and because teachers in Sweden usually follow their class in subsequent years, three of the four grade 2 teachers who participated in round 4 participated with the same class the previous year in grade 1 .

As can be seen in Table 1, we drew on several sources of data. A teacher log book contained teachers' reflections about the planning and teaching of lessons. In rounds 1 and 2 , teachers were asked to send in, for every lesson, what they planned to modify and to maintain, their reflections on the taught lesson, and what they would do differently should 
Table 1 Overview development phase

\begin{tabular}{|c|c|c|c|}
\hline \multicolumn{3}{|l|}{ School year 2016-2017 } & \multirow{2}{*}{$\begin{array}{l}\text { School year 2017-2018 } \\
\text { Round } 4\end{array}$} \\
\hline Round 1 & Round 2 & Round 3 & \\
\hline November 2016 & February-April 2017 & April-May 2017 & September 2017 \\
\hline Grade 1 & Grade 2 & Grade 1 & Grade 2 \\
\hline Aim: & Aim: & Aim: & Aim: \\
\hline $\begin{array}{l}\text { Test how teachers take up support } \\
\text { in teachers' guide } \\
\text { Test how the alternative classroom } \\
\text { practices work out in class, } \\
\text { including Open Response and } \\
\text { Reengagement Lessons }\end{array}$ & $\begin{array}{l}\text { Test preliminary ideas: improve } \\
\text { readability by means of structur- } \\
\text { ing of information, and use } \\
\text { of lesson slides during lesson } \\
\text { enactment }\end{array}$ & $\begin{array}{l}\text { Test feasibility of one complete } \\
\text { chapter } \\
\text { Test lesson format }\end{array}$ & $\begin{array}{l}\text { Test readability and ease of use } \\
\text { of the materials, including the } \\
\text { inclusion of lesson slides in the } \\
\text { lesson description } \\
\text { Check how video fragments about } \\
\text { (working with) the materials are } \\
\text { perceived and used }\end{array}$ \\
\hline Subtraction, 4 lessons & Multiplication, 10 lessons & $\begin{array}{l}\text { Measurement and two-dimen- } \\
\text { sional figures, } 11 \text { lessons }\end{array}$ & $\begin{array}{l}\text { Multiplication as a repeated addi- } \\
\text { tion, } 3 \text { lessons }\end{array}$ \\
\hline 5 teachers: A, B, C, D, E & 6 teachers: A, F, G, H, I, J & 3 teachers: $\mathrm{A}, \mathrm{B}, \mathrm{C}$ & 4 teachers: $\mathrm{A}, \mathrm{C}, \mathrm{D}, \mathrm{K}$ \\
\hline Data sources: & Data sources: & Data sources: & Data sources: \\
\hline Log book teachers A, B, C, D, E & Log book teachers A, G & Log book teachers A, B, C & Whole group reflection meeting at \\
\hline $\begin{array}{l}6 \text { lesson observations: teachers } \\
\text { A, B, D }\end{array}$ & $\begin{array}{l}21 \text { lesson observations: teachers } \\
\text { A, G, I }\end{array}$ & $\begin{array}{l}\text { Curriculum reading log teachers } \\
\mathrm{B}, \mathrm{C}\end{array}$ & $\begin{array}{l}\text { end of lesson series: teachers A, } \\
\mathrm{C}, \mathrm{D}, \mathrm{K}\end{array}$ \\
\hline $\begin{array}{l}\text { Brief post-lesson conversation } \\
\text { teacher D }\end{array}$ & $\begin{array}{l}\text { Whole group reflection meeting: } \\
\text { teachers } \mathrm{A}, \mathrm{F}, \mathrm{G}, \mathrm{H}, \mathrm{I}, \mathrm{J}\end{array}$ & $\begin{array}{l}3 \text { lesson observations: teachers } \\
\text { B, C }\end{array}$ & \\
\hline $\begin{array}{l}\text { Whole group reflection meeting: } \\
\text { teachers } \mathrm{A}, \mathrm{B}, \mathrm{C}, \mathrm{E}\end{array}$ & & $\begin{array}{l}\text { Notes of post-lesson interview } \\
\text { teacher B }\end{array}$ & \\
\hline $\begin{array}{l}\text { Teacher notes during whole-group } \\
\text { meeting: teachers A, B, C, E }\end{array}$ & & $\begin{array}{l}\text { Whole group reflection meeting: } \\
\text { teachers A, B }\end{array}$ & \\
\hline
\end{tabular}

they teach the lesson again. In round 3, teachers filled in a log book as well, but were not asked to do so as specified as in rounds 1 and 2 . They were asked to submit, at a moment of their preference, their reflections on the lessons and on the provided supports.

Further, lesson observations were carried out and complemented with (usually informative) post-lesson conversations. In round 3 , two teachers filled in a curriculum reading $\log$ for two lessons - an idea we borrowed from the ICUBiT project (Remillard 2013). The curriculum reading log is a copy of a lesson in the teachers' guide in which teachers marked in different colors what they read, what they planned to use as described in the teachers' guide, and what they planned to modify or did not plan to use but thought was informative. The post-lesson interview with teacher B in round 3 built on the information we got from the teacher's curriculum reading log combined with the actual observation of the taught lesson.

All of the abovementioned sources served as input for a reflective whole-group meeting at the end of each round. At the beginning of the meeting in round 1 , teachers made notes about their reflections on the different types of support. These notes are also part of the data corpus of this study.

\subsection{Coding and analysis}

Coding of the data was carried out by the first author, ${ }^{3}$ and focused on identifying the type of information. The following codes and subcodes, emerging from the data, were applied:

- Difficulties with the taught lessons, including difficulties for students and for teachers.

- Difficulties in use of the teachers' guide.

- Reported modifications, including simplifying the lesson by means of splitting up the group/lesson, other modifications, and tips from teachers.

- Use of teachers' guide before/during/after teaching.

- Reactions against the provided supports, including the instructional sequence, anticipating student thinking, tips from a fictitious teacher, lesson slides, discussions, exit tickets, and timing indications.

Analysis of the coded data occurred in three steps. In a first step, the analysis focused on better understanding the content that was covered by the codes. Looking across the codes helped to identify three themes of focus in teachers'

\footnotetext{
${ }^{3}$ It should be viewed as a limitation of the study that the coding was carried out by only one person.
} 
reactions on the use of our materials: (1) the structure of lessons with several lesson phases, (2) particular lesson activities, and (3) use of the teachers' guide. In a second step, we structured the data within these three themes, which led to dimensions within each. Teachers' reactions in relation to the first two themes related to student difficulties, difficulties experienced by teachers, appreciated supports, and modifications and tips from teachers. Teachers' reactions in relation to the third theme related to the use of the teachers' guide before, during, and after teaching, the central role of lesson slides, and related tips. In so doing, we composed three matrices, one per theme, in which we cross-tabulated the abovementioned dimensions with the different sources of data we were drawing on. This allowed us to connect each dimension with corresponding excerpts from the data. In step 4, we analyzed teachers' reactions per dimension, thus covering several sources of data. The outcome of this analysis, addressing research questions 1 and 2 , is presented in the following section.

\section{Findings}

For 25 years, process goals such as reasoning, participating in discussions, and problem solving have had a central place in the national curriculum for mathematics in Sweden. National evaluations and research (Boesen et al. 2014) as well as our own experiences working intensively with hundreds of teachers reveal that these process goals, however, are not yet commonplace in Swedish mathematics classroom practices, and that teachers are in need of, and ask for, concrete support to alter the common practice in which students work mainly individually in their workbooks.

Many of the classroom observations we carried out within this project revealed classroom practices that were quite aligned with our intent. The feedback we received from teachers, however, also caused specific difficulties to surface, as experienced by teachers and students. The text below consists of three major sections. In the first section, "Classroom practices", we briefly describe the classroom practices, drawing primarily on 30 lesson observations. The major focus, however, is on the feedback we received from teachers about working with our materials. Towards that end, the second section zooms in on teachers' reactions upon planning and teaching the proposed lessons with our materials. The third section, then, focuses on how teachers made use of the teachers' guide.

\subsection{Classroom practices}

Lesson observations during rounds 1, 2, and 3 revealed in many cases a picture of classroom practices that matched well with the intended lessons as described in the lesson guides. In all 30 observed lessons, teachers had a central role in that they structured the lessons, initiated lesson phases, closed them down and moved to subsequent lesson phases, set up and guided activities, and managed the classroom participation structures. Twenty-eight lessons started by describing the lesson goals. Except for the 9 lessons in round 2 taught by Teacher A, which included only in respectively lesson 2 and lesson 5 explicit connections to other lessons and a reflection at the end of the lesson, most of the other lessons included these aspects. Respectively 20 and 18 of the remaining 21 lessons included explicit connections to previous or future lessons and a reflection on the lesson or lesson goal at the end of the lesson. In 12 of the 14 lessons for which an "exit ticket" was provided, the close of the lessons included students filling in this exit ticket, which enabled the teacher to get a snapshot of how well students were understanding the content of the lesson. Teachers led whole-class discussions and students worked in pairs, discussing concepts and approaches to solve tasks. Although challenging, particularly for the grade 1 students, teachers indicated during whole-group meetings that they thought it was good for students to "talk math so early and to talk about concepts, which is different from other curriculum programs" (Round 3, Whole group meeting, Teacher A).

However, the feedback we got from teachers revealed that it was also challenging for students and teachers to learn and teach mathematics in the way we proposed. The following section zooms in on how teachers reacted on planning and teaching the lessons and on the provided support in the teachers' guide.

\subsection{Teachers' reactions on teaching the proposed lessons with our materials}

In the two sections below, we present findings in relation to how teachers reacted concerning the planning and teaching of lessons that include several lesson phases and specific lesson activities. As described in Sect. 5.2, we include in our analysis student difficulties that were mentioned, difficulties that teachers experienced, how teachers reacted on provided supports, and modifications and suggestions mentioned by the teachers.

\subsubsection{Teachers' reactions on the lesson structure}

A major difference between the lessons as tried out by the teachers and the custom practice when teaching mathematics in Sweden relates to the structuring of the lessons. In contrast to the common practice in which students primarily work individually using their student textbook, and where the teacher has a reactive role in that she/he is a facilitator of the student-textbook interaction, the lessons as tried out consisted of the three standard lesson phases introduction, 
core, closing down, with the first two of these phases usually consisting of several activities. Instead of a reactive role, we assumed that teachers could take up a proactive role in structuring the lesson and setting up activities. According to the teachers, students were not used to this, as indicated in the following excerpt: ${ }^{4}$

It felt so long, they are not used to have a lesson that is like, now is the start of the lesson and we work, we work and I steer the whole time during 50 minutes or, even when I off course otherwise also teach lessons, but it's more, one needs to break off with something [...]. (Round 1, Whole-group meeting, Teacher C).

The following excerpt by the same teacher indicates that also teachers are not used to this lesson structure and to relying on a teachers' guide: "Too many moments per lesson-hard to memorize, being steered by the paper, when it's not you own fabrication" (Round 1, Whole-group meeting teacher notes, Teacher C). Also mentioned by 3 of the 5 teachers in round 1 is that lessons consisting of several phases cause difficulties for students to stay focused: "Several lessons have felt very inconstant with several breaking points, in grade 1 these breaking points need focus and one needs to start over from the beginning with the focus" (Round 1, Log book, Teacher E). Even during the wholegroup meeting in round 4,3 of the 4 teachers mentioned that these several lesson moments make the lessons challenging for students.

In round 1,4 of the 5 teachers' reported difficulties related to taking up the lesson structure when planning for the lesson and deciding on when to move on to a next lesson moment during teaching, as illustrated in the following excerpt: "Concluding, I think that it is hard for me as a teacher to take up so many different phases and to know how to steer the lesson when lessons have so many goals" (Round 1, Log book, Teacher D). Even in rounds 3 and 4, one and three teacher(s) respectively mentioned related difficulties. For instance, following a lesson observation in round 3 , we had a post-lesson interview with teacher B about the lesson and how she prepared for the lesson. Input for the interview came from the completed curriculum reading log and the observed lesson. From the curriculum reading log, it appeared that the teacher frequently read the sections that described when to move on to a next phase. When talking about this during the interview, the teacher mentioned several times that she thinks this is useful information for her, because she finds it at times hard to decide whether to move on or not, to the next lesson phase.

\footnotetext{
$\overline{4}$ This excerpt, as well as all other excerpts, are translated into English.
}

The difficulties as experienced by the teachers got reflected in the support they valued. As illustrated in the following excerpt, descriptions of how lessons and lesson phases related to one another were appreciated and used by all teachers in rounds 1 and 3, by 2 of the 3 observed teachers in round 2, and by 3 of the 4 teachers in round 4 .

And then there is the lesson content in relation to previous and upcoming lessons. That is good, just to see what we have worked with, what are we going to work with now, and what comes next. [Teacher A is nodding.] One sees, there one sees also the red thread, you see like what the thought is. It's not, we don't do something isolated just now. And this is also something, one can talk about this with the students: the previous time we did this, today we are going to do that, and then next time we will continue working with this here. (Round 3, Whole-group meeting, Teacher B)

When describing the difficulties as experienced by the teachers, we mentioned that teacher B made use of the support within the lesson description that talks about when to move on to the next lesson phase. Another teacher also mentioned that he made use of the support that summarizes the lesson phases during teaching: "I appreciated the boxes in the lessons a lot and made use of them to keep the lesson in the right compass direction" (Round 1, Whole-group teacher notes, Teacher A).

\subsubsection{Teachers' reactions on teaching particular lesson activities}

Apart from the difficulties that both students and teachers experienced with the structuring of lessons into several lesson phases, both teachers and students had difficulties with certain activities in these phases. Based on the feedback we received from teachers, students had difficulties (a) in participating in discussions and to give feedback on each other's work, (b) in explaining and visualizing their thinking, and (c) with new social norms.

Student difficulties in relation to participating in discussions and to giving feedback were mentioned in all trial rounds, including during the whole-group meeting in round 4 by teacher $C$ who participated in rounds 1 and 3 as well. Thus, although her students had participated in 14 previous lessons that centered on discussing mathematics in rounds 1 and 3, it appeared that they still had serious difficulties in actively participating in these activities in round 4 . Illustrative of the student difficulties mentioned by the teachers is the following reflection from teacher A on lesson 4 in round 1: "What went less well was that the lesson became a monologue. The discussion was non-existent among the students and it felt like I had to pull the information out of them" (Round 1, Log book, Teacher A). 
Also, four of the five teachers who participated in round 1 wrote in their log books that students have difficulties in explaining their thinking: "A lot of students had difficulties in showing how they knew that one fence was bigger than the other. It is new for the students to write/draw how they solved a task. We did that part orally" (Round 1, Log book, Teacher C) and "Many also had difficulties showing by means of drawings, even when being supported by an adult" (Round 1, Log book, Teacher B).

Furthermore, in all 4 rounds, there were indications that students had difficulties accepting the new social norms. As we write below, students at times did not see the need to explain their thinking, thought that discussing mathematics is not really mathematics, and had difficulties seeing errors as a learning opportunity.

There were moments where it appeared that students did not really think there was a need to explain their thinking: "Answers like 'good' came up frequently, but without further development as to why things went well or how they did" (Round 1, Log book, Teacher A), and:

What was more difficult in this group compared to the previous one was that there were several students who were not willing to show how they knew that the rabbit's garden was bigger than the chicken ['s garden]. 'It is something that you just see', was a common answer. (Round 1, Log book, Teacher D)

Also, some students thought that discussing mathematics is not really mathematics, as evidenced in the following excerpt:

Especially in lesson 7, I felt a greater participation among the students. There were many students active in the discussion and I felt they were getting hold of the " 2 stars and a wish" activity. Unfortunately, at the end of the lesson, some students asked when we'd start with mathematics [...]. Apparently, it's only the individual work that is considered mathematics and not the discussions. (Round 2, Log book, Teacher A)

Also, it appeared that students had difficulties accepting that making errors is okay. During the whole-group meeting in round 3, teacher A mentioned that a strong student had difficulties accepting that she/he did not succeed in completing a task. The teacher described that it helped to refer to the lesson goals, which stated that students would practice a capacity, to assure the student that it was not bad not to master the capacity by the end of the lesson.

Zooming now in on teacher difficulties, in round 1,4 of the 5 teachers indicated that it was hard to guide the discussions and to build on student work during discussions. During the whole-group meeting in Round 1 teacher B said: "It is funny to hear, because I had a very hard time to get it started, to get the discussion started, there were just a couple that, it was very directed, it was very hard to get the discussion started with them". During the same meeting, there was a conversation between teachers $\mathrm{B}, \mathrm{C}$, and D concerning the difficulties in selecting and building on student work. Below is an excerpt of that conversation:

Teacher D: "I felt, many student examples, when it was written, when one would choose several student examples that one would like to have got some student examples to fall back on in case you don't find one. What is it we would, what, a little bit more steering. Because it is not always so easy to find, or what do you think we should look after. Ah, but it's not always so easy".

Teacher B: "This is also my opinion, it was good information. But, just that when one feels like you have 22 examples, which one will I take? There was nothing that maybe, felt so-so, worked to make use of".

Teacher D: "No, but if you'd had some examples then you could take, yeah but, bring in one's own too".

However, in all 4 rounds, teachers indicated that they valued the student examples that were provided: "Complete student examples can be good, because I experienced that there was not a choice of examples amongst my students" (Round 1, Whole-group teacher notes, Teacher B) and "I made use of the planning between [lessons] 3 and 4. Clear about to lift out student examples. Good with the tip to be anonymous" (Round 1, Whole-group teacher notes, Teacher C).

The exit tickets, which gave the teachers at the end of the lesson a snapshot of how well students master the content, were valued by 8 of the 10 teachers who participated in Rounds $2,3,4 .^{5}$ Teachers used these exit tickets primarily to monitor student progress: "The exit tickets showed then that those who had difficulties at first, understood it at the end of the lesson when no one could use any help" (Round 3, Log book, Teacher A), and:

The exit tickets were good, because they showed that about half of the class was not completely sure about how to measure. For the next half class lesson, I grouped the students based on the results on the exit tickets. [...] I made use of the exit tickets as a close down of the lesson. They showed that about half the class was unsure about the rectangle and square. Therefore, I devoted the next math lesson to repeating the names. (Round 3, Log book, Teacher C)

Finally, as evidenced in the teachers' log books, their notes during the whole-group meeting or during the wholegroup discussion, all five teachers in round 1 appreciated the principles for discussion to help the students participate in

\footnotetext{
5 Exit tickets were not included in the materials tried out in round 1.
} 
discussions. Teachers mentioned that these principles were a good start for future discussions.

\subsection{Teachers' use of the teachers' guide}

Below, we present findings in relation to how teachers reacted upon the use of the teachers' guide. As described in Sect. 5.2, our analysis relates to use of the teachers' guide before/during/after teaching, the central role of lesson slides, and related teacher suggestions. The teachers used the teachers' guide primarily for planning of the lesson and to a much lesser extent during and after teaching the lesson. They also relied to a strong extent on the lesson slides we provided, even when planning the lesson. We write more about each of these in the two sections below.

\subsubsection{Use of the teachers' guide prior to, during, and after teaching}

As to the planning of lessons, 8 of the 10 teachers who participated in rounds 1 and 2-these were the rounds when teachers tried out the materials for the first time ${ }^{6}$ - mentioned that this was time consuming. Teacher $\mathrm{E}$ wrote in her $\log$ book in round 1: "I am definitely not as used as you are in relation to this thinking of mathematics, but it took a long time to really understand lesson by lesson. Have really spent a long time reading and structuring the lessons". Teacher B wrote in her notes during the whole-group meeting in round 1: "A lot of text to read-Required many readings before all pieces fell on their place [...]". Even during the whole-group meeting in round 3, this teacher mentioned that these lessons required a lot of preparation time:

Teacher B: "Spontaneously, I felt would all lesson series be like this, then we cannot, it really feels a lot, spontaneously".

Curriculum designer: "What do you mean, a lot of content, is it a lot of content or do we ask you to read a lot of things?"

Teacher B: "A lot to read".

[...]

Teacher B: "It's not only math we have to do, we also have a lot of other things to do. Grade 1 students also have..."

[...]

Curriculum designer: "You might not be able to work like this every day".

Teacher B: "No, no..."

\footnotetext{
${ }^{6}$ Except for teacher A, who participated in round 1 prior to partici-
} pating in round 2 .
Notably, with more experience trying out the materials, and after having taken into account teachers' remarks and comments concerning the lay-out in rounds 1 and 2, such as 'Difficult to see/perceive 'the support' in the running text and better by means of bullet points and boxes" (Round 1, Whole-group meeting teacher notes, Teacher B), and "Important to know where the lesson is going to. Could have been clearer lifted, marked" (Round 1, Whole-group meeting teacher notes, Teacher C), only 1 of the 5 participating teachers in rounds 3 and 4 mentioned that it took a lot of time to prepare for teaching the lessons.

Three out of the four teachers who participated in the whole-group meeting in round 4 mentioned that they did not use the teachers' guide during teaching. Teacher $\mathrm{C}$ mentioned that she had the teachers' guide with her during teaching but that she did not have time to check it, that she had freestyled but thought it went fine during the lesson by means of relying on the lesson slides. Teacher K also mentioned that she couldn't check the teachers' guide during teaching either. Teacher D said that she had the teachers' guide next to her just in case, but did not check it. Only teacher A said that he had the teachers' guide open and skimmed it sometimes during teaching. This is also the teacher who said during the whole-group meeting in round 1 that he relied on the teachers' guide during teaching to keep the lesson on the right track.

Two teachers in round 1 mentioned that they used the support in the lesson description to reflect on the lessons after teaching; they made use of the summaries of lesson phases and descriptions of the connections between the lesson phases:

I think it was nice also, when one had done a lesson, one could check for yourself a bit, euh, was it as I had thought, was it as it was thought? One could also go back. That was nice, I think. (Round 1, Whole-group meeting, Teacher D)

\subsubsection{Central role of lesson slides}

Teachers focused on the lesson slides, for instance, to structure the lesson:

The lesson slides were good to group the students around; they were simple and easy to understand. They helped to remind me of everything and to "frame in" the lesson. It was a bit unclear in what order they should come. It might be good to mark in the teachers' guide where these slides will be used. [...] They helped to keep the structure of the lesson. I sometimes think that it is hard to round off/connect lessons, but under these lessons the lesson slides have been a good help. (Round 3, Log book, Teacher B) 
Whereas the lesson slides initially were developed as an additional support for teachers during teaching, it appeared that teachers allocated the lesson slides a central role not only during teaching, but during planning of the lesson as well. Eight of the 10 teachers who participated in rounds 2, 3 , and $4^{7}$ mentioned the usefulness of the lesson slides when planning the lesson. Teacher D, for instance mentioned during the whole-group meeting in round 4 that after preparing the lesson during the evening before, on the morning before teaching, she checked the lesson slides and the lesson overview pages (consisting of the lesson goals, needed materials, and a summary of the lesson phases). Furthermore, the lesson slides were used by the teachers in 20 of the 24 observed lessons in rounds 2 and 3.

Teachers' strong focus on the lesson slides when planning a lesson was at times at the cost of their focus on other information to be read in the teachers' guide. For instance, during the whole-group meeting in round 3, teacher A mentioned that at times, when planning for a lesson, he printed out the page with the slides and wrote notes on that page but didn't check so much the actual guidelines and support in the teachers' guide. Teacher K also mentioned that when preparing for a lesson, she focused most on the lesson slides and primarily skimmed the guidelines and support in the teachers' guide. Also illustrative in this regard, as revealed in round 3 by teacher B's curriculum reading logs, is the teacher's stronger focus on the lesson slides at the cost of other information in the teachers' guide toward the end of a lesson series of 11 lessons.

Teachers' focus on the lesson slides also was reflected in the many teacher suggestions to improve (working with) these lesson slides during the whole-group meetings in rounds 2, 3 and 4. For instance, in round 3, teacher A proposed including the lesson slides in the actual lesson description instead of representing all the slides together on the final page, "Because if one wants to follow the lessons more like a slave, one could do so by means of the lesson slides, for instance for less experienced teachers".

\section{Concluding discussion}

Curriculum programs have been and are still often used as a vehicle to initiate reform. For about 20 years, the assumption has been that rather than talking through teachers by means of directing their actions, curriculum programs should talk to teachers about the background of the advocated approaches and practices to facilitate reform (Ball and Cohen 1996; Davis and Krajcik 2005; Remillard 2000).

7 Lesson slides were not included in the materials tried out in round 1.
Recently, this assumption has been challenged and complicated by Remillard and Reinke (2012). Their analysis of four American teachers' guides suggests that curriculum programs, to some extent, can also be educative by talking through teachers, for instance, by means of offering directive support about "new pedagogical repertoire and routines, allowing teachers to consider and try out new questions to ask, words to use, and instructional moves to make". (p. 13). We found this suggestion appealing because, when reflecting on the findings of how teachers in Sweden interact with and reflect upon the curriculum program, we saw a strong tendency to appreciate directive support.

For both types of support, be it talking through or to teachers, a central assumption is that teachers have a central role in organizing and steering the mathematics lessons. As we described earlier concerning the educational context in Sweden, Swedish teachers typically have had a reactive role during mathematics lessons, motivating students and facilitating their work in textbooks. A central focus of this paper has been teachers' reactions towards, and take up of, supports that have typically been associated with a central teacher role in organizing and steering mathematical lessons. Although teachers reacted to and took up supports that talk to them about, for instance, the instructional sequence related to individual lessons and lesson series, teachers' main focus was on supports that are directive in nature and that talk through them, such as use of the lesson slides to structure the lessons, principles for discussions, and the use of exit tickets. This use and quest for directive, explicit support, we argue, is closely connected to the Swedish educational context that has been dominated by an implicit pedagogy. In other words, the lack of explicit support to act in classrooms in national steering documents, teacher education programs and among colleagues (Ryve et al. 2016) has resulted in a quest for concrete suggestions and frameworks about how to act in planning and enacting classroom practices. Also illustrative in this regard is the teachers' quest for more steering in relation to selecting student examples rather than a focus on understanding possible student difficulties. This, and the fact that the observed classroom practices differed substantially from custom practices (e.g., Boesen et al. 2014) resonates with Remillard and Reinke's (2012) suggestion that curriculum programs can be educative by means of talking through teachers.

At the same time, falling back so strongly on these directive supports has likely hindered teachers from a flexible use of the teachers' guide. This indicates that, when rolling out a complete curriculum program, the facilitation of alternative classroom practices and development of teachers' capacity to use curriculum programs well does not necessarily go hand in hand. It appeared that teacher modifications to the lessons usually related only to making the lessons manageable by splitting up the lesson into more than one lesson moment, 
splitting up the student group, or by making an appeal for additional instructors in the classroom. Few initiatives and explicit discussions of how to adapt or reorganize tasks, activities or mathematical ideas were found in our data. We relate this to the Swedish educational context in which teachers have had very few opportunities to develop several aspects of mathematical knowledge for teaching, including an effective use of teaching support.

A resulting concern in the project is the conceptualization of teachers' learning trajectories in relation to the use of a curriculum program to reorganize classroom practices. Using Brown's (2009) terms, our experiences suggest that Swedish teachers move from improvising to offloading the design of the lesson to the program, before eventually making adaptations. Relating this trajectory to the appreciated teacher support in this study suggests that when moving from improvising to offloading, teachers might be served with support that talks through them, whereas support that talks to teachers might be crucial in moving from offloading to adapting. Research suggests that teachers might learn by using these materials over time (e.g., Choppin 2009), combined with explicit support in how to use these materials (e.g., Gavin et al. 2013). It has to be seen in future interactions with teachers to what extent this plays out in the Swedish context, and how best to explicitly support teachers' learning. In contrast to students who successively learn new content, teachers typically work with the same materials during the sequence of multiple years. We therefore contend that the research field on teachers' use of curriculum programs would benefit from a continued focus on the conceptualization of teachers' learning trajectories in relation to curriculum use.

To conclude, our findings suggest that characteristics of current classroom practices, teachers' role in classrooms, the history of implicit/explicit teacher support, and teachers' experiences using teachers' guides, explain how teachers interact with and reason about the curriculum program, and therefore are crucial when designing a new research-based mathematics curriculum program.

Acknowledgements We wish to thank the blind reviewers for their thoughtful comments and insights as well as the language editor, Norma Presmeg.

Open Access This article is distributed under the terms of the Creative Commons Attribution 4.0 International License (http://creativeco mmons.org/licenses/by/4.0/), which permits unrestricted use, distribution, and reproduction in any medium, provided you give appropriate credit to the original author(s) and the source, provide a link to the Creative Commons license, and indicate if changes were made.

\section{References}

Ball, D. L., \& Cohen, D. K. (1996). Reform by the book: What is-or might be-the role of curriculum materials in teacher learning and instructional reform. Educational Researcher, 25(9), 6-8, 14.

Boesen, J., Helenius, O., Bergqvist, E., Bergqvist, T., Lithner, J., Palm, T., \& Palmberg, B. (2014). Developing mathematical competence: From the intended to the enacted curriculum. The Journal of Mathematical Behavior, 33, 72-87.

Brown, M. W. (2009). The teacher-tool relationship. Theorizing the design and use of curriculum materials. In J. T. Remillard, B. A. Herbel-Eisenman \& G. M. Lloyd (Eds.), Mathematics teachers at work: Connecting curriculum materials and classroom instruction (pp. 17-36). New York: Routledge.

Bryk, A. S., Gomez, L. M., Grunow, A., \& LeMahieu, P. G. (2015). Learning to improve: how America's schools can get better at getting better. Cambridge: Harvard University Press.

Century, J., \& Cassata, A. (2016). Implementation research: Finding common ground on what, how, why, where, and who. Review of Research in Education, 40(1), 169-215.

Choppin, J. M. (2009). Curriculum-context knowledge: Teacher learning from successive enactments of a standards-based mathematics curriculum. Curriculum Inquiry, 39(2), 287-320. https ://doi.org/10.1111/j.1467-873X.2009.00444.x.

Choppin, J. M. (2011a). The impact of professional noticing on teachers' adaptations of challenging tasks. Mathematical Thinking and Learning, 13(3), 175-197. https://doi.org/10.1080/10986 065.2010.495049.

Choppin, J. M. (2011b). Learned adaptations: Teachers' understanding and use of curriculum resources. Journal of Mathematics Teacher Education, 14(5), 331-353.

Davis, E. A., Beyer, C., Forbes, C. T., \& Stevens, S. (2011). Understanding pedagogical design capacity through teachers' narratives. Teaching and Teacher Education, 27(4), 797-810. https ://doi.org/10.1016/j.tate.2011.01.005.

Davis, E. A., \& Krajcik, J. S. (2005). Designing educative curriculum materials to promote teacher learning. Educational Researcher, 34(3), 3-14.

Davis, E. A., Palincsar, A. S., Arias, A. M., Bismack, A. S., Marulis, L. M., \& Iwashyna, S. K. (2014). Designing educative curriculum materials: A theoretically and empirically driven process. Harvard Educational Review, 84(1), 24-52.

Fowler, F. C., \& Poetter, T. S. (2004). Framing French success in elementary mathematics: Policy, curriculum, and pedagogy. Curriculum Inquiry, 34(3), 283-314.

Gavin, M. K., Casa, T. M., Adelson, J. L., \& Firmender, J. M. (2013). The impact of challenging geometry and measurement units on the achievement of Grade 2 students. Journal for Research in Mathematics Education, 44(3), 478-509.

Gueudet, G., \& Trouche, L. (2009). Towards new documentation systems for mathematics teachers? Educational Studies in Mathematics, 71(3), 199-218. https://doi.org/10.1007/s1064 9-008-9159-8.

Hemmi, K., Krzywacki, H., \& Koljonen, T. (2017). Investigating Finnish teacher guides as a resource for mathematics teaching. Scandinavian Journal of Educational Research, 1-18.

Hemmi, K., \& Ryve, A. (2015). Effective mathematics teaching in Finnish and Swedish teacher education discourses. Journal of Mathematics Teacher Education, 18(6), 501-521.

Hill, H. C., \& Charalambous, C. Y. (2012). Teacher knowledge, curriculum materials, and quality of instruction: Lessons learned and open issues. Journal of Curriculum Studies, 44(4), 559-576. https ://doi.org/10.1080/00220272.2012.716978. 
Kennedy, M. M. (2016). How does professional development improve teaching? Review of Educational Research, 86(4), 945-980. https ://doi.org/10.3102/0034654315626800.

Remillard, J. T. (2005). Examining key concepts in research on teachers' use of mathematics curricula. Review of Educational Research, 75(2), 211-246. https://doi.org/10.3102/0034654307 5002211.

Remillard, J. T. (2000). Can curriculum materials support teachers' learning? Two fourth-grade teachers' use of a new mathematics text. The Elementary School Journal, 100(4), 331-350. https:// doi.org/10.1086/499645.

Remillard, J. T. (2013). Beyond the script: Educative features of five mathematics curricula and how teachers use them. Paper presented at the AERA annual meeting, San Francisco.

Remillard, J. T., \& Heck, D. J. (2014). Conceptualizing the curriculum enactment process in mathematics education. ZDM Mathematics Education, 46(5), 705-718.

Remillard, J. T., \& Reinke, L. (2012). Complicating scripted curriculum: Can scripts be educative for teachers? Paper presented at the AERA annual meeting, Vancouver, British Columbia, Canada.

Remillard, J. T., Van Steenbrugge, H., \& Bergqvist, T. (2016). A crosscultural analysis of the voice of six teacher's guides from three cultural contexts. Paper presented at the AERA annual meeting, Washington, USA.
Ryve, A., Hemmi, K., \& Börjesson, M. (2013). Discourses about school-based mathematics teacher education in Finland and Sweden. Scandinavian Journal of Educational Research, 57(2), 132-147.

Ryve, A., Hemmi, K., \& Kornhall, P. (2016). Skola på vetenskaplig grund: Natur och kultur.

Stein, M. K., \& Kaufman, J. H. (2010). Selecting and supporting the use of mathematics curricula at scale. American Educational Research Journal, 47(3), 663-693. https://doi.org/10.3102/00028 31209361210

Stein, M. K., \& Kim, G. (2009). The role of mathematics curriculum materials in large-scale urban reform. In J. T. Remillard, B. A. Herbel-Eisenman \& G. M. Lloyd (Eds.), Mathematics teachers at work: Connecting curriculum materials and classroom instruction (pp. 37-55). New York: Routledge.

Svenska Läromedel. (2018). Kvalitetspolicy för tryckta och digitala läromedel. http://svenskalaromedel.se/kvalitetspolicy/.

Van Steenbrugge, H., Remillard, J. T., \& Bergqvist, T. (2015). How mathematics curriculum programs can be designed to accommodate a flexible restructuring by the teacher. Paper presented at the AERA annual meeting, Chicago, USA.

Vygotsky, L. S. (1978). Mind in society: The development of higher mental process. Cambridge: Harvard University Press. 